\title{
Reseña de Vega, Lope de, San Nicolás de Tolentino, ed. Roy Norton, Kassel, Edition Reichenberger, 2016, 346 pp. ISBN: 978-3-944244-52-5
}

\author{
Natalia Fernández Rodríguez \\ Universität Bern \\ SUIZA \\ natalia.fernandez@rom.unibe.ch
}

[Hipogrifo, (issn: 2328-1308), 6.2, 2018, pp. 821-823]

Recibido: 31-05-2018 / Aceptado: 20-06-2018

DOI: http://dx.doi.org/10.13035/H.2018.06.02.56

Roy Norton se encarga de realizar la primera edición crítica de San Nicolás de Tolentino, comedia de santos compuesta por Lope de Vega hacia 1614. Aparte de la edición princeps, incluida en la Veinticuatro parte de las comedias del Fénix (Zaragoza, 1641), los testimonios con los que cuenta el editor se reducen a las ediciones de Menéndez Pelayo (Madrid, 1894; Madrid, 1965), Sainz de Robles (Madrid, 1955) y Puente Peña (Santiago de Chile, 1984). Queda fuera de toda duda, por tanto, la necesidad de ofrecer un texto depurado y, desde luego, un estudio profundo de la comedia y su contexto que, hasta la fecha, no se había abordado. El editor cumple este cometido con éxito y solvencia, y su edición de San Nicolás de Tolentino trasciende sus límites para convertirse en un estudio muy relevante dentro de la historia y las vicisitudes del género comedia de santos.

Es sabido que, a pesar de la enorme fecundidad de las piezas hagiográficas en tiempos de la comedia nueva y del éxito sostenido durante todo el siglo XVII, la crítica no siempre se mostró favorable a un género híbrido entre lo sagrado y lo profano en el que los impulsos de lo dramático vertían, a veces, soluciones rayanas en la heterodoxia. A partir de la última década del siglo XX y, en especial, en lo que va del XXI, las cosas han cambiado y se han multiplicado los proyectos, individuales y colectivos, que se esfuerzan por sacar a la luz textos en su mayoría inéditos y por escudriñar las claves compositivas de las comedias de santos. En el caso concreto, y especialmente relevante, de Lope de Vega, la empresa -inestimable pero sin duda insuficiente - llevada a cabo por Menéndez Pelayo permitió acceder a los textos de sus comedias hagiográficas, pero era necesaria una labor crítica rigurosa que fuese completando la bibliografía lopesca y situando la comedia de santos en su lugar dentro de la obra del Fénix. El trabajo del grupo Prolope, de la Universidad Autónoma de Barcelona, con su edición por partes de las comedias de Lope, ofrece 
a la comunidad investigadora textos rigurosos y estudios detallados de las piezas hagiográficas (la última por el momento, Lo fingido verdadero incluida en la parte $X V I^{1}$ ). $Y$, junto a estas, las ediciones individuales, que permiten una mayor profundización tanto en los estudios como en las notas, han logrado que las comedias de santos y sus circunstancias de composición y puesta en escena se hayan convertido en asuntos de creciente interés para lectores e investigadores.

La presente edición de San Nicolás de Tolentino ofrece un estudio muy completo tanto sobre algunos aspectos clave de la pieza desde el punto de vista compositivo y temático, como sobre cuestiones textuales. El editor redacta el estudio introductorio en inglés y presenta las notas en castellano, tal vez para mantener la coherencia con el propio texto y no obligar al lector a estar cambiando constantemente de lengua. No ponemos reparos a esta solución que, creemos, facilita más que otra cosa. Tampoco sobra el «Resumen del estudio» en castellano que, en seis páginas, destaca los ejes fundamentales de la introducción y orienta al lector. El estudio está dividido en seis secciones que tratan los asuntos que el editor considera «más interesantes y útiles para la comprensión de San Nicolás dentro del contexto de la tradición de la comedia de santos» (p. 1; traducción mía). Es de agradecer que se omitan las cuestiones generales sobre el teatro del Siglo de Oro que no estén directamente relacionadas con la obra y que se profundice justamente en los aspectos vinculados con las circunstancias de composición y los ejes estructurales y temáticos de la pieza. La estructura del estudio introductorio es perfectamente lógica y, aunque no se haga explícito, hay dos bloques: lo hagiográfico y lo dramático. Las tres primeras secciones se centran en las cuestiones sobre la devoción a Nicolás de Tolentino, las fuentes de Lope y la dramatización de la materia hagiográfica; las tres últimas abordan asuntos singularizadores de la pieza como el personaje del gracioso - uno de los más peculiares, por cierto, de la comedia de santos lopesca- la presencia de lo sobrenatural o la versificación. La presentación exhaustiva de las fuentes hagiográficas en las que pudo basarse Lope, lejos de limitarse a un mero inventario, se somete a un análisis preciso sobre cuáles fueron los elementos aprovechados por el Fénix y cuáles no, algo mostrado de forma gráfica en un útil cuadro sinóptico (Tabla 2). La sección tercera, donde se pregunta el editor, con afortunado neologismo, si Lope está elaborando una "hagiograficción", se centra justamente en la forma en que la visión dramática del Fénix le hace trascender los condicionantes de la hagiografía. Esta forma de abordar la comedia de santos, teniendo muy presente el trasfondo piadoso ofrecido por las fuentes hagiográficas y valorando hasta dónde se respetan y dónde empiezan a trascenderse es, a nuestro parecer, el camino más riguroso para comprender las claves compositivas del género y de las piezas concretas.

En la cuarta sección del estudio, el editor se centra en la figura del gracioso, Ruperto, y en cómo su presencia se compatibiliza con un cierto contexto devocional. No hay nada que objetar al análisis de Norton, salvo que no tenga en cuenta

1. Coordinada por Florence d'Artois y Luigi Giuliani, Madrid, Gredos, 2017. 
los estudios de Ramón Sugranyes y Javier Rubiera² sobre el elemento cómico en las comedias de santos. Aunque ambos trabajos se centren en obras de Calderón, ofrecen planteamientos que podrían haber resultado útiles para el análisis, como la comprensión por parte del primero de la comicidad como contrapunto que, creemos, es aplicable justamente al caso de San Nicolás de Tolentino. En la sección quinta, el análisis del elemento sobrenatural en la comedia parte de los planteamientos de Dassbach (1997), el artículo, sin duda, de referencia en la materia. Norton analiza con detenimiento los episodios sobrenaturales que se incluyen en la pieza desde esa doble perspectiva sugerida por Dassbach: la espectacularidad de la puesta en escena, por un lado, y la excepcionalidad del santo, por otro - de nuevo, lo dramático y lo hagiográfico imbricados, esta vez, en la dimensión escenográfica-. Finaliza su estudio introductorio con un análisis de la versificación, una sinopsis argumental de la comedia y la presentación de la historia textual y editorial.

Desde el punto de vista ecdótico, se sigue el texto de la princeps y, en algunas ocasiones muy puntuales se enmienda, bien siguiendo las propuestas de los cuatro testimonios modernos, bien a criterio del propio editor. En su mayoría las decisiones editoriales son correctas, aunque hay algún caso dudoso. Por ejemplo, no resulta totalmente necesaria la enmienda 'el sol' por 'al sol', compartido por todos los testimonios, en el verso 368: 'y me deshace como el sol la cera'. Tal vez la lectura propuesta por el editor resulte más natural desde el punto de vista sintáctico, pero creemos que podría aceptarse sin problemas una lectura 'y me deshace como al sol la cera'. Lo mismo sucede en el verso 379, 'que yo no sé qué queda, el bien gozado', donde todos los testimonios leen 'qué quede'. No es incorrecta la propuesta del editor, pero tampoco lo sería la lectura de la princeps. Probablemente debido a criterios editoriales específicos se incluyen en el aparato crítico algunas enmiendas o variantes que tal vez no deberían considerarse tales. Es el caso, entre otros, de los ejemplos que siguen:

$$
\begin{array}{ll}
253 & \text { hallara ] hallará P } \\
404 & \text { Ah ] Ha P } \\
1035 & \text { ésta ] está P } \\
1428 & \text { cocodrilo ] cocodrillo P }
\end{array}
$$

Se trata, creemos, de variantes ortográficas, pero no ecdóticas. E, incluso, en el caso de las tildes, tratándose de la tipografía del Siglo de Oro, las constantes oscilaciones hacen improductivo un cotejo a este nivel. En cualquier caso, estos detalles no desmerecen el rigor de un trabajo editorial, por lo demás, impecable.

La actual edición de San Nicolás de Tolentino constituye, por tanto, una aportación necesaria a los estudios sobre teatro religioso del Siglo de Oro y permite al lector e investigador actual acercarse a una interesante comedia lopesca mediante un texto cuidado y un completo aparato de notas explicativas.

2. Sugranyes, Ramón, «Complejidad temática y contrapunto en el teatro barroco. Los graciosos en El mágico prodigioso», Cuadernos hispanoamericanos, 355, 1980, pp. 112-126; Rubiera, Javier, «El elemento cómico en la comedia de santos (I)», Anuario calderoniano, 3, 2010, pp. 307-320. 